\title{
Die schweizerische Uhrenindustrie und die asiatischen Schwellenländer
}

L'horlogerie suisse et les nouveaux pays industriels asiatiques

Jean-François Blanc

\section{(2) OpenEdition}

1 Journals

Édition électronique

URL : http://journals.openedition.org/sjep/1188

DOI : 10.4000/sjep. 1188

ISSN : 1663-9677

Éditeur

Institut de hautes études internationales et du développement

\section{Édition imprimée}

Date de publication : 1 janvier 1988

Pagination : 203-221

ISSN : 1660-5926

\section{Référence électronique}

Jean-François Blanc, «Die schweizerische Uhrenindustrie und die asiatischen Schwellenländer »,

Schweizerisches Jahrbuch für Entwicklungspolitik [En ligne], 7| 1988, mis en ligne le 05 avril 2013,

consulté le 08 septembre 2020. URL : http://journals.openedition.org/sjep/1188; DOI : https://doi.org/ 10.4000/sjep. 1188

\section{Ce document a été généré automatiquement le 8 septembre 2020}

(C) The Graduate Institute 


\title{
Die schweizerische Uhrenindustrie und die asiatischen Schwellenländer
}

\author{
L'horlogerie suisse et les nouveaux pays industriels asiatiques
}

Jean-François Blanc

\section{NOTE DE L'ÉDITEUR}

Zusammenfassung auf Deutsch. Volltext auf Französisch in Annuaire suisse de politique de développement: „L'horlogerie suisse et les nouveaux pays industriels asiatiques”, http:// aspd.revues.org/1343.

\section{RÉSUMÉS}

In diesem Beitrag untersucht der Verfasser die Zusammenhänge, die sich zwischen dem Umstrukturierungsprozess der Uhrenindustrie in der Schweiz und der Errichtung neuer Uhrenproduktions- und -exportstatten in den Schwellenländern Asiens (Hongkong, Südkorea, Taiwan und Singapur) ergeben. Er geht dabei von der Tatsache aus, dass der in den vergangenenen Jahren eingetretene technologische Wandel weltweit zu einer Umverteilung der Uhrenindustrie (Verlagerung in die Billiglohnländer) geführt hat.

Im ersten Teil wird der Uhrenhandel zwischen der Schweiz und den asiatischen Schwellenländern untersucht. Dabei werden folgende Tendenzen festgestellt: Ab 1970 bedeutende Einfuhren von Billiguhren und Uhrenbestandteilen aus den asiatischen Schwellenländern (und anderen asiatischen Ländern). Bis 1980 umfangreiche schweizerische Lieferungen an Uhrenbestandteilen in diese neuen Produktionsstätten, danach Rückgang dieses Trends. Seit einigen Jahren ein gewisser Wiederaufschwung des Schweizer Uhrenexports (vor 
allem elektronische Uhren), nach einem langwierigen Umstrukturierungsprozess der schweizerischen Uhrenindustrie.

Im zweiten Teil wird die Niederlassungspolitik der Schweizer Uhrenindustrie in den asiatischen Schwellenländern analysiert. An der Fallstudie Hongkong wird gezeigt, dass die Produktionsverlagerung zu einem relativ späten Zeitpunkt und in beschränktem Ausmass erfolgte. Dies lässt sich durch die besondere Struktur der Schweizer Uhrenindustrie (langsames Vordringen der neuen Technologien, Rückgang der Marktpräsenz, starker Beschäftigungsrückgang in der Branche ) erklären.

In seinen Schlussfolgerungen führt der Verfasser am Beispiel Hongkongs eine Reihe von Gründen an, die eine nuancierte Bewertung der Bemühungen der Schweizer Uhrenindustrie zur Produktionsverlagerung in die asiatischen Schwellenländern ratsam erscheinen lassen. Er kommt zu dem Schluss, dass sich statt einer Opposition zwischen den jungen asiatischen Industrieländern und den traditionellen Industriestaaten derzeit eine Tendenz zur wachsenden internationalen Arbeitsteilung in der Uhren Industrie abzeichnet; hierbei scheint Hongkong eine mittlere Position zwischen den modernen Forschungs- und Entwicklungszentren (Japan, Schweiz) und den „Wirtschaftszonen” der Billiglohnländer (China, Thailand, Malaysia und Philippinen) einzunehmen. 